\title{
DESIGN AND OPTIMIZATION OF SIDE IMPACT BEAM OF CAR
}

\author{
PRASAD GHADASHI ${ }^{1}$, VAISHNAVI ALONI ${ }^{2}$, SUSHANT KANWADE ${ }^{3} \&$ RUPESH JADHAV $^{4}$ \\ ${ }^{1,2,3}$ UG Student, School of Mechanical and Civil Engineering, MIT Academy of Engineering, Alandi, Pune, India \\ ${ }^{4}$ Assistant Professor, School of Mechanical and Civil Engineering, MIT Academy of Engineering, Alandi, Pune, India
}

ABSTRACT
Road safety is a very crucial concern nowadays. Many people die in road accidents every day. This research is based on
previous researches on the side impact beam or intrusion beam of vehicle. The objective of this paper is to analyse and
optimize the side impact beam based on resistance force and specific energy absorption during impact. Side impact causes
more fatal injuries than front \& rear impacts. And as we all know; passenger safety is the most important criteria while
designing an automotive body. Side impact crashes can be fatal as there is no room for large deformation to protect the
passenger from lateral impact. The side Door Intrusion Beam is one of the main energy-absorbing parts in event of a side
impact. Till date, many types of research have been carried on side-impact \& ways to reduce it. This paper begins with an
overview of various cross-sections of the side impact beam, various materials, and their applications and importance. Also,
we have done a simulation of a three-point bending test on a side impact beam with different combinations of material and
cross-sections.
KEYWORDS: Side Impact Beam, Hypermesh, Three-Point Bending Test, Specific Energy Absorption.

Received: Apr 20, 2021; Accepted: May 10, 2021; Published: May 15, 2021; Paper Id.: IJAUERDJUN20212

\section{INTRODUCTION}

In many accidents, the occupants are injuring severely and sometimes losing lives. There are different types of accidents, which are happening daily, like frontal, side-impact, rollover, and rear impact, etc. Side impact collisions are too dangerous as there is no space for more deformation of the side structures when compared with frontal collisions [2]. Side impact collision is the second most type of collision happening after frontal collisions. At an extreme level, the research is going on to increase the safety of vehicles by decreasing the effectiveness of collisions. With time, there are successful results in safeguarding the occupants from severe injuries during collisions [2]. The crashworthiness design of vehicles for passive safety aims to obtain a strong, crushproof passenger surviving cell connected to several components able to absorb and dissipate energy in a stable and controlled manner [16]. In the case of a side-impact collision, the side door beam which is installed in the door played a very important role to absorb a lot of energy, thereby reducing the amount of energy transferred to the occupants [16]. Intrusion beams are mainly designed as a feature in car doors for the security of the driver and passenger during the side-impact collision. Its purpose is to absorb and withstand the impact loads, which are developed during the side-impact collision. The deformation level cannot provide space for the side airbag to deploy. As the number of vehicles determining accident rate is increasing and higher and higher requirements are raised to their impact estimation and passengers' security, investigations on the above-ground vehicles' safety elements and energy-absorbing structures are very actual. Investigations of safety elements absorbing energy were initiated for the cases most often occurring during accidents - crashes and runs down [6]. As a result of this investigation, recommendations for deformation elements of front zones of vehicle, later used for rear body zones, 
were performed. Gradually investigations of other safety elements were performed [6]. Analysis of car accidents testifies that side impacts make up $30 \%$ of all impacts and $35 \%$ of them are fatal ones [16].

\section{METHODOLOGY}

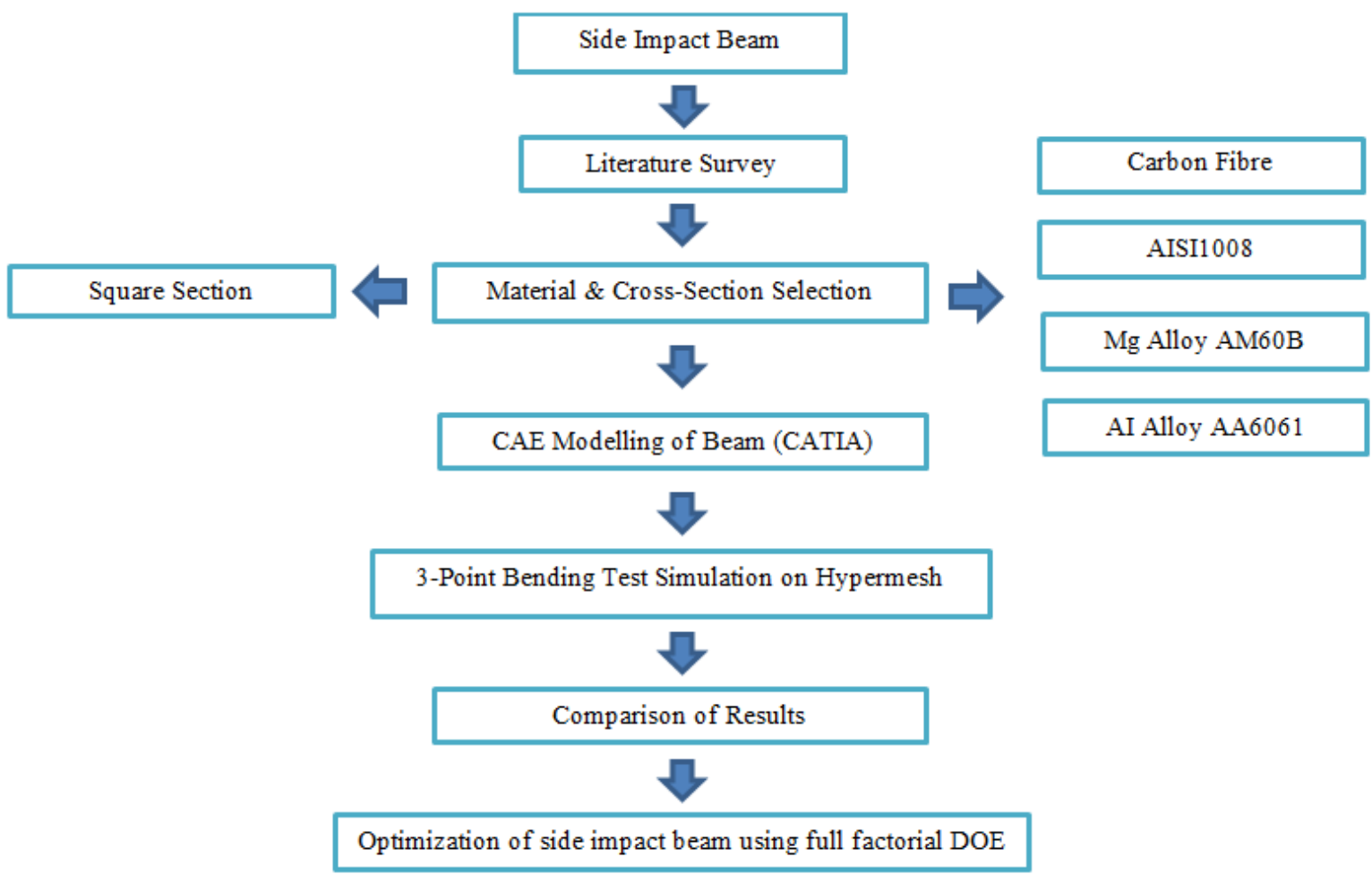

Figure 1: Methodology of our Project

The methodology of this research is to design and optimize the intrusion beam capable of absorbing maximum impact energy. These side-impact beams are fitted in the side doors of a passenger car to protect the passenger during a collision.

We studied various literature related to the side impact beam of the vehicle. From the study, we concluded that further improvement in the intrusion beam can be done by different combinations of best-suited parameters like crosssection, core material, composite laminates, etc. For the selection of material, cross-section \& composite we compare results of various research paper related to intrusion beam design \& we finalized Aluminium Alloy AA6061[10], Magnesium Alloy AMB60 [22] \& AISI1008 [3] as our beam material \& layer of carbon fibre [7] to be applied on two sides of the beam. We kept the section of the beam as a square with a single groove [21].

We decided to work on the following combinations for our project:

Table 1: Aluminium Alloy (AA6061) material Beam \& Composite Thickness

\begin{tabular}{|c|c|c|c|c|c|c|c|c|c|}
\hline Material & \multicolumn{9}{c|}{ Aluminium Alloy AA6061 } \\
\hline Beam Thickness (mm) & \multicolumn{3}{|c|}{1} & \multicolumn{3}{|c|}{1.2} & \multicolumn{3}{|c|}{1.4} \\
\hline Composite Thickness (mm) & 1 & 1.5 & 2 & 1 & 1.5 & 2 & 1 & 1.5 & 2 \\
\hline
\end{tabular}


Table 2: Magnesium Alloy (AM60B) Material Beam and Composite Thickness

\begin{tabular}{|c|c|c|c|c|c|c|c|c|c|}
\hline Material & \multicolumn{9}{|c|}{ Magnesium Alloy AM60B } \\
\hline Beam Thickness (mm) & \multicolumn{3}{|c|}{1} & \multicolumn{3}{|c|}{1.2} & \multicolumn{3}{|c|}{1.4} \\
\hline Composite Thickness (mm) & 1 & 1.5 & 2 & 1 & 1.5 & 2 & 1 & 1.5 & 2 \\
\hline
\end{tabular}

Table 3: AISI1008 Material Beam \& Composite Thickness

\begin{tabular}{|c|c|c|c|c|c|c|c|c|c|}
\hline Material & \multicolumn{9}{|c|}{ AISI1008 } \\
\hline Beam Thickness (mm) & \multicolumn{3}{|c|}{1} & \multicolumn{3}{|c|}{1.2} & \multicolumn{3}{|c|}{1.4} \\
\hline Composite Thickness (mm) & 1 & 1.5 & 2 & 1 & 1.5 & 2 & 1 & 1.5 & 2 \\
\hline
\end{tabular}

We studied different samples of intrusion using three-point bending test simulation on hyper mesh software using Optistruct solver. We simulated a total of 27 different samples using a three-point bending test. Then we further optimized the intrusion beam using the full factorial DOE technique.

\subsection{Three-Point Bending Test Simulation}

We used CATIA \& Hypermesh for modeling \& simulation respectively. We took help from a previous research paper [3], where authors have done both simulation \& actual experimentation. The experimental test door beam deformation pattern is similar to the FEA simulation. Hence, we decided to set up the exact model of simulation for our study.

We applied steel material for indenter \& supports. Appropriate material \& thickness were given to the beam as per cases mentioned in Table 1, Table 2, Table 3. The overall cross-section of the beam was $55 \mathrm{x} 55 \mathrm{~mm} \&$ the length was $1000 \mathrm{~mm}$.

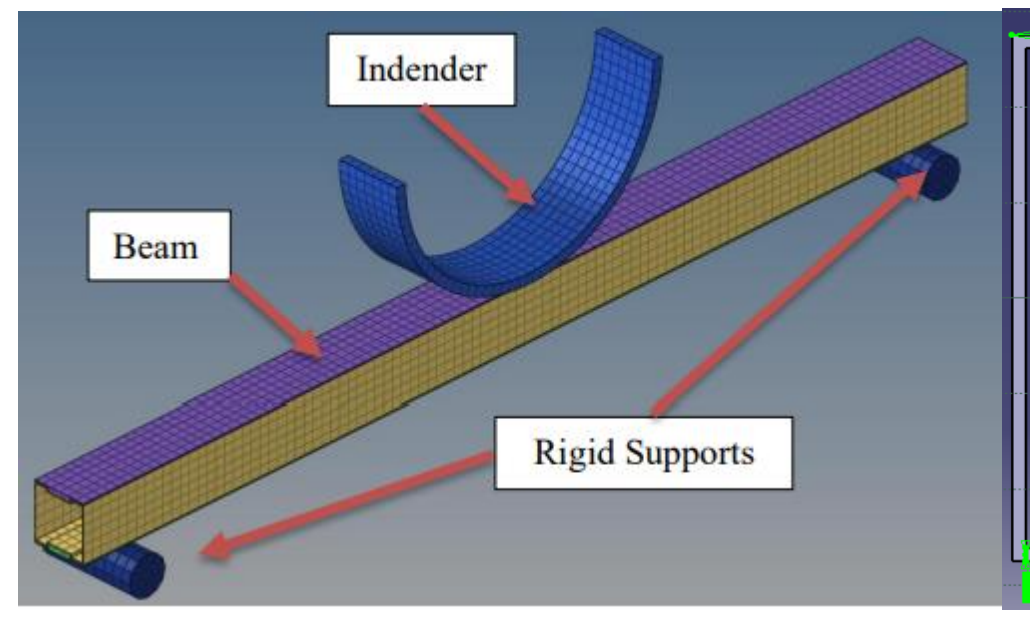

Figure 2: Simulation setup used in Hypermesh

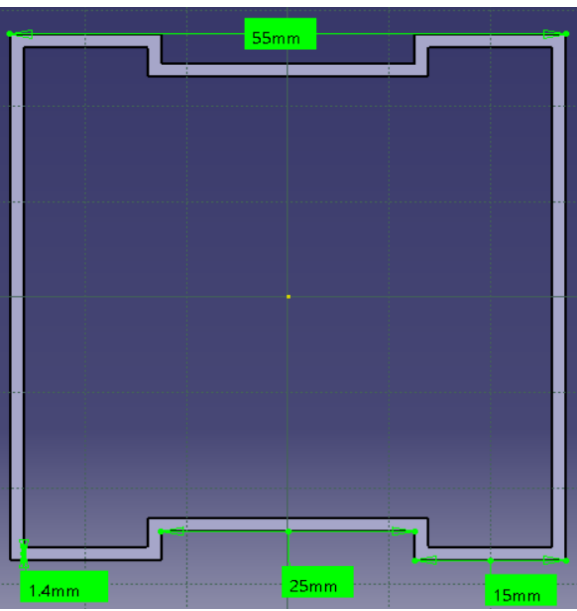

Figure 3: Cross-section of Beam

We applied the following boundary conditions for our setup.

- Distance between rigid supports is $900 \mathrm{~mm}$.

- The beam is rigidly constrained in all DOF (Degree of freedom) on two ends which is represented by rigid 
cylinder supports of diameter $40 \mathrm{~mm}$.

- An indenter of diameter $300 \mathrm{~mm}$ is used, which intrudes into the beam. It had five DOFs with the only displacement along the negative Z-axis.

- Surface to surface contact is applied between i. 'indenter' and 'Side door beam' ii. 'Cylinder supports' and 'Side door beam' 5. An imposed displacement is applied to the indenter \& it is placed at the centre of the beam as shown in setup figure 4.

\subsection{Optimization using Design of Experiment (DOE):}

DOE is a structured, organized method for determining the relationship between factors affecting a process and the output of that process. A full factorial design of the experiment measures the response of every possible combination of factors and factor levels. These responses are analysed to provide information about every main effect and every interaction effect [23]. A full factorial DOE is practical when fewer than five factors are being investigated as testing all combinations of factor levels becomes too expensive and time-consuming with five or more factors [23]. In our experiment, factors affecting the resistance force \& SEA are beam material, beam cross-section thickness \& composite thickness. The total number of factors affecting the output is three. Also, numerical simulation requires less time $\&$ no cost; hence we decided to perform full factorial DOE.

Details of experimentation are given below:

Table 4: Details of factors \& Levels Used in Full Factorial DOE

\begin{tabular}{|c|c|c|c|}
\hline Factors & \multicolumn{3}{|c|}{ Levels } \\
\hline Material & Al Alloy & Mg Alloy & AISI1008 \\
\hline Beam Thickness & $1 \mathrm{~mm}$ & $1.2 \mathrm{~mm}$ & $1.4 \mathrm{~mm}$ \\
\hline Composite Thickness & $1 \mathrm{~mm}$ & $1.5 \mathrm{~mm}$ & $2 \mathrm{~mm}$ \\
\hline
\end{tabular}

There are three levels for each factor. Hence total of 27 combinations is required [Formula for total combinations $=($ Levels $\wedge$ factors)].

\section{RESULTS}

\subsection{Three-Point Bending Test Results:}

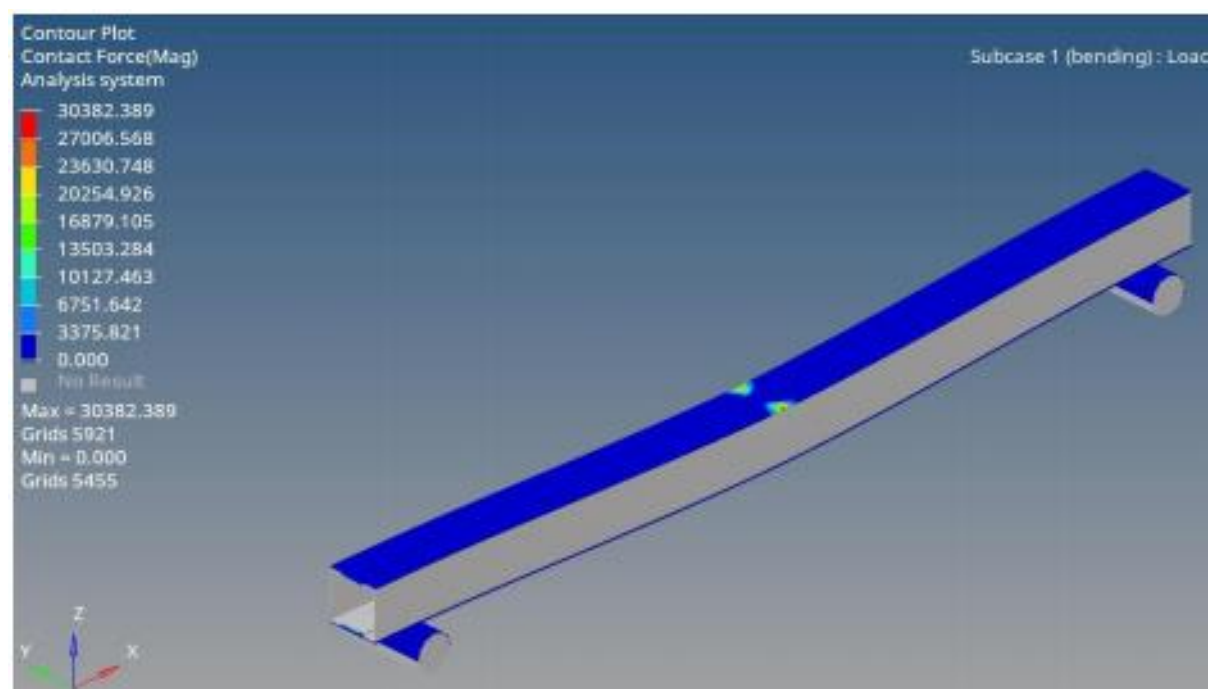

Figure 4: Contact Force $1.2 \mathrm{~mm}$ thick section with $1.5 \mathrm{~mm}$ thick composite (AISI 1008) 


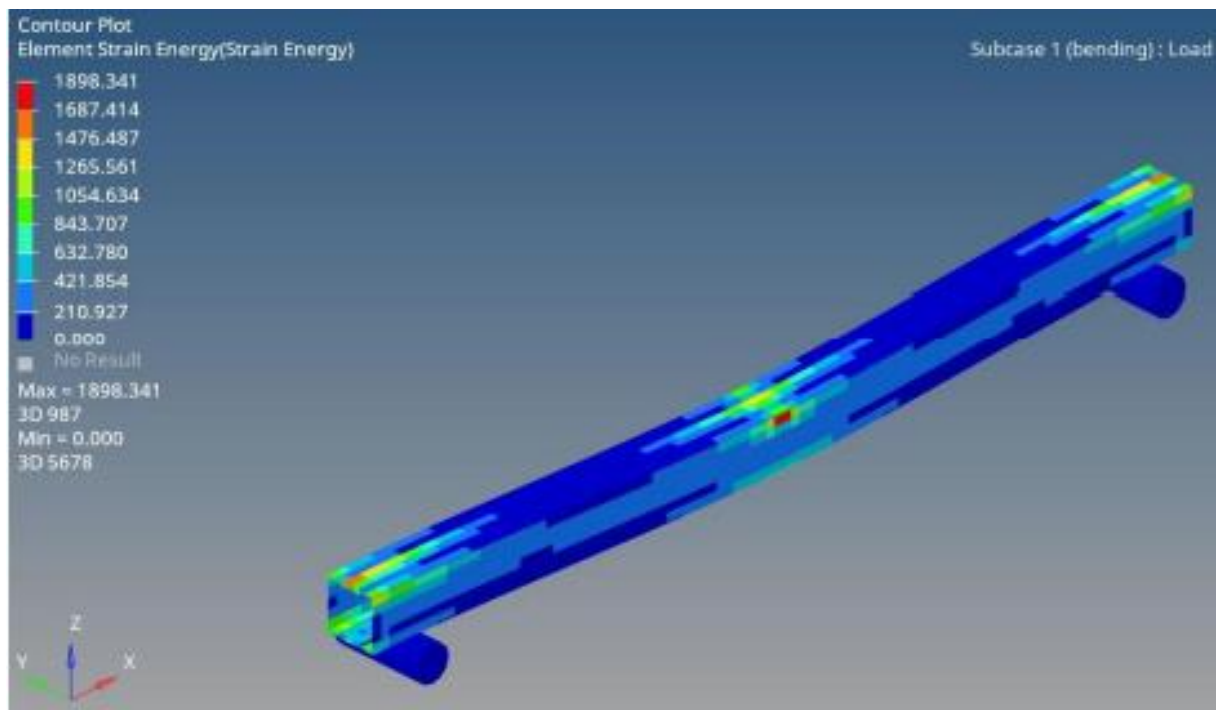

Figure 5: Strain Energy 1.2 mm thick section with $1.5 \mathrm{~mm}$ thick Composite (AISI 1008)

The above results are of contact force \& strain energy obtained from simulation of three-point bending test on Hypermesh software.

Table 5: Numerical Simulation Results of three-point Bending Tests

\begin{tabular}{|c|c|c|c|c|c|c|}
\hline No & Materials & $\begin{array}{c}\text { Beam } \\
\text { Thick } \\
\text { ness }\end{array}$ & $\begin{array}{c}\text { Composite } \\
\text { Layer } \\
\text { Thickness }\end{array}$ & $\begin{array}{c}\text { Contact } \\
\text { Force }(\mathbf{N})\end{array}$ & $\begin{array}{c}\text { Strain } \\
\text { Energy }(\mathbf{J})\end{array}$ & $\begin{array}{c}\text { SEA } \\
(\mathrm{J} / \mathrm{kg})\end{array}$ \\
\hline \multirow{9}{*}{1} & \multirow{9}{*}{ Al Alloy } & \multirow{3}{*}{$1 \mathrm{~mm}$} & $1 \mathrm{~mm}$ & 10409.266 & 925.94 & 853.400 \\
\hline & & & $1.5 \mathrm{~mm}$ & 15081.523 & 1179.371 & 996.090 \\
\hline & & & $2 \mathrm{~mm}$ & 16619.887 & 1249.653 & 974.008 \\
\hline & & \multirow{3}{*}{$\begin{array}{c}1.2 \\
\mathrm{~mm}\end{array}$} & $1 \mathrm{~mm}$ & 14565.707 & 1126.020 & 935.232 \\
\hline & & & $1.5 \mathrm{~mm}$ & 16338.323 & 1257.344 & 964.960 \\
\hline & & & $2 \mathrm{~mm}$ & 17925.057 & 1298.701 & 926.320 \\
\hline & & \multirow{3}{*}{$\begin{array}{c}1.4 \\
\mathrm{~mm}\end{array}$} & $1 \mathrm{~mm}$ & 14962.094 & 1101.683 & 832.715 \\
\hline & & & $1.5 \mathrm{~mm}$ & 17622.455 & 1335.890 & 939.444 \\
\hline & & & $2 \mathrm{~mm}$ & 19263.053 & 1414.585 & 930.036 \\
\hline \multirow{8}{*}{2} & \multirow{8}{*}{ AISI 1008} & \multirow{3}{*}{$1 \mathrm{~mm}$} & $1 \mathrm{~mm}$ & 20032.285 & 1324.431 & 585.513 \\
\hline & & & $1.5 \mathrm{~mm}$ & 27318.121 & 1608.103 & 681.110 \\
\hline & & & $2 \mathrm{~mm}$ & 29273.371 & 1772.677 & 720.600 \\
\hline & & \multirow{3}{*}{$\begin{array}{l}1.2 \\
\mathrm{~mm}\end{array}$} & $1 \mathrm{~mm}$ & 25252.742 & 1429.611 & 548.163 \\
\hline & & & $1.5 \mathrm{~mm}$ & 30382.389 & 1898.341 & 701.271 \\
\hline & & & $2 \mathrm{~mm}$ & 32256.488 & 1982.043 & 706.358 \\
\hline & & \multirow{2}{*}{$\begin{array}{c}1.4 \\
\mathrm{~mm}\end{array}$} & $1 \mathrm{~mm}$ & 29502.266 & 2089.231 & 705.106 \\
\hline & & & $1.5 \mathrm{~mm}$ & 33349.461 & 2163.181 & 706.460 \\
\hline
\end{tabular}




\begin{tabular}{|c|c|c|c|c|c|c|}
\hline & & & $2 \mathrm{~mm}$ & 35389.516 & 2167.299 & 685.637 \\
\hline \multirow{9}{*}{3} & \multirow{9}{*}{$\begin{array}{c}\text { Magnesium Alloy } \\
\text { AM60B }\end{array}$} & \multirow{3}{*}{$1 \mathrm{~mm}$} & $1 \mathrm{~mm}$ & 8438.241 & 813.253 & 926.256 \\
\hline & & & $1.5 \mathrm{~mm}$ & 13267.151 & 954.263 & 976.727 \\
\hline & & & $2 \mathrm{~mm}$ & 14608.793 & 987.339 & 917.601 \\
\hline & & \multirow{3}{*}{$1.2 \mathrm{~mm}$} & $1 \mathrm{~mm}$ & 11718.500 & 919.164 & 959.461 \\
\hline & & & $1.5 \mathrm{~mm}$ & 13957.626 & 1036.579 & 980.680 \\
\hline & & & $2 \mathrm{~mm}$ & 15327.509 & 1153.898 & 998.181 \\
\hline & & \multirow{3}{*}{$\begin{array}{c}1.4 \\
\mathrm{~mm}\end{array}$} & $1 \mathrm{~mm}$ & 13203.775 & 968.345 & 932.894 \\
\hline & & & $1.5 \mathrm{~mm}$ & 14225.559 & 1122.905 & 987.603 \\
\hline & & & $2 \mathrm{~mm}$ & 15633.990 & 1194.059 & 966.067 \\
\hline
\end{tabular}

From the above results, the maximum contact force $(35.38 \mathrm{kN})$ is resisted by an AISI1008 beam with $1.4 \mathrm{~mm}$ thickness $\&$ $2 \mathrm{~mm}$ composite thickness, but the specific energy absorption by the same sample is only about $685.72 \mathrm{~J} / \mathrm{kg}$. Above mentioned beam has a weight of $3.16 \mathrm{~kg}$ which is the highest among all samples. This extra weight would affect the fuel economy of the vehicle. Hence, optimization needed to be performed on the beam. The optimized beam should have maximum SEA \& optimum resistance force.

\subsection{Design of Experiment (DOE) Results:}

\section{Contact Force:}

The main effect plot $\&$ interaction plots of contact force are given below:

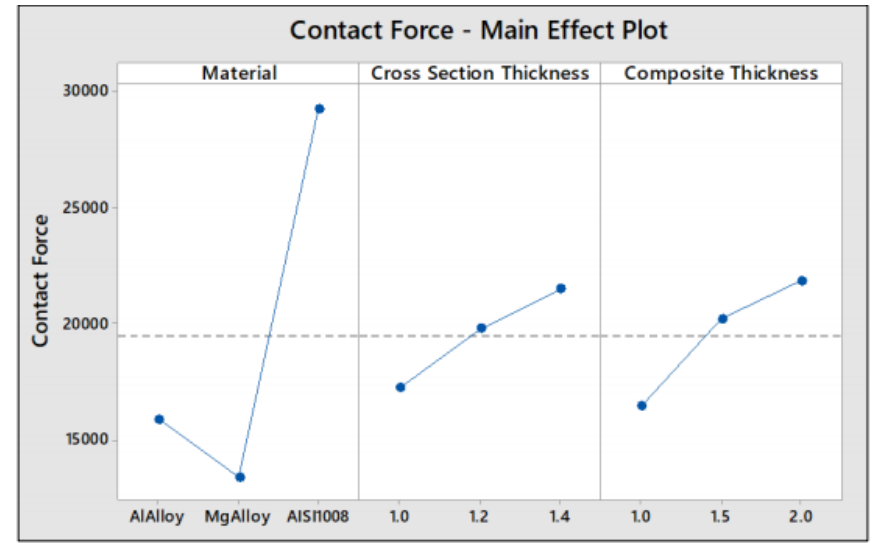




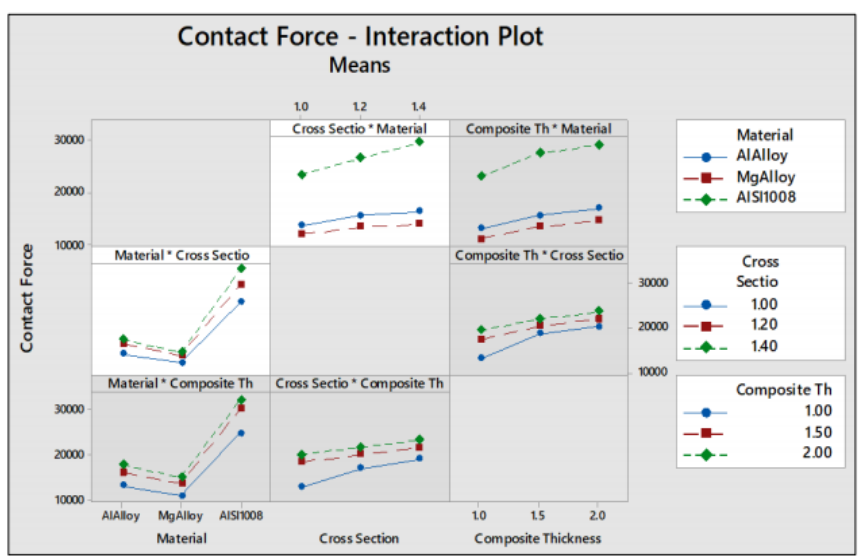

Figure 6: Main Effect Plot \& Interaction Plot Of Contact Force

From the main effect plot of contact force, it is seen that intrusion beam material's contribution is significant compared to cross-section thickness \& composite thickness. AISI1008 provides the highest contact force among all materials. The interaction plot is also showing the dominance of AISI1008 material on contact force.

Specific Energy Absorption (SEA):

The main effect plot of specific energy absorption (SEA) is given below:
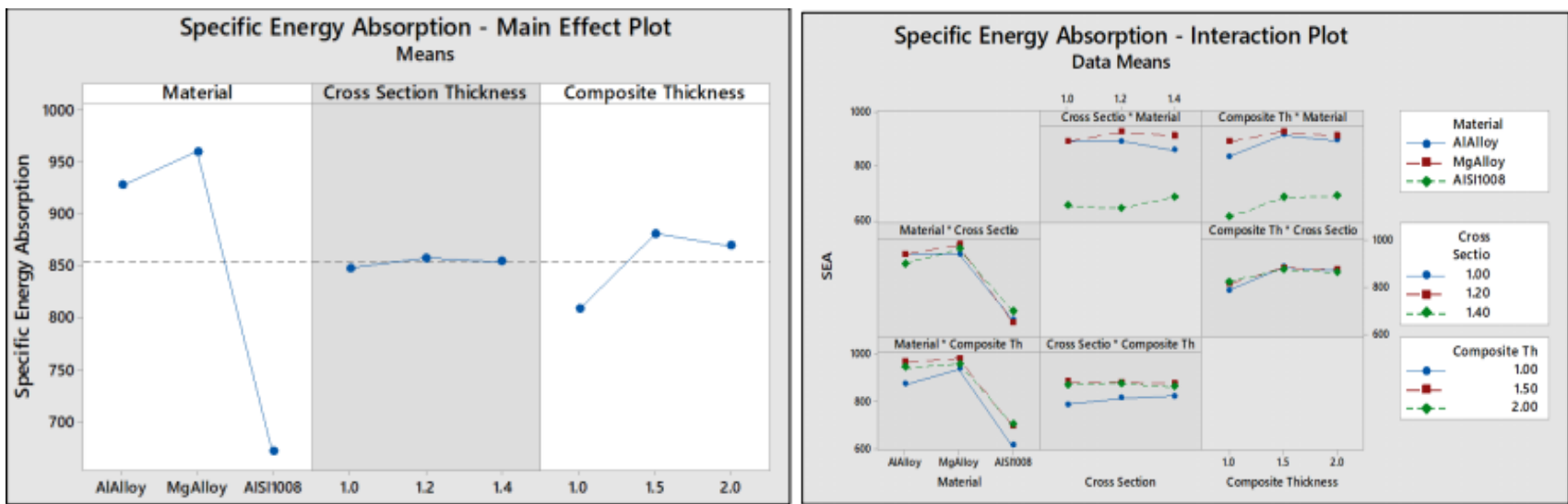

Figure 7: Main Effect Plot \& Interaction Plot of Specific Energy Absorption (SEA)

Although AISI1008 is the best-suited material for contact force, SEA for AISI1008 is very low compared to the other two materials. Composite thickness \& cross-section thickness are not contributing significantly. SEA for samples with Magnesium alloy AM60B is highest. The interaction plot of SEA is showing the dominance of magnesium alloy AM60B on the SEA of the beam. From the above results, it is seen that we need to optimize the sample which can have maximum SEA \& optimum contact force. Here, the response optimization technique is used. In the response optimizer, a target contact force of $17.5 \mathrm{kN} \&$ SEA of $950 \mathrm{~J} / \mathrm{kg}$ is applied.

\begin{tabular}{|c|c|c|c|c|c|c|c|}
\hline \multicolumn{8}{|c|}{ Response Optimizer: Setup } \\
\hline Response & & & Lower & Target & Upper & Weight & Importance \\
\hline Contact Force & Target & - & 15000 & 17500 & 20000 & 1 & 1 \\
\hline SEA & Target & $=$ & 900 & 950 & 980 & 1 & 1 \\
\hline
\end{tabular}

Figure 8: Response optimizer setup 

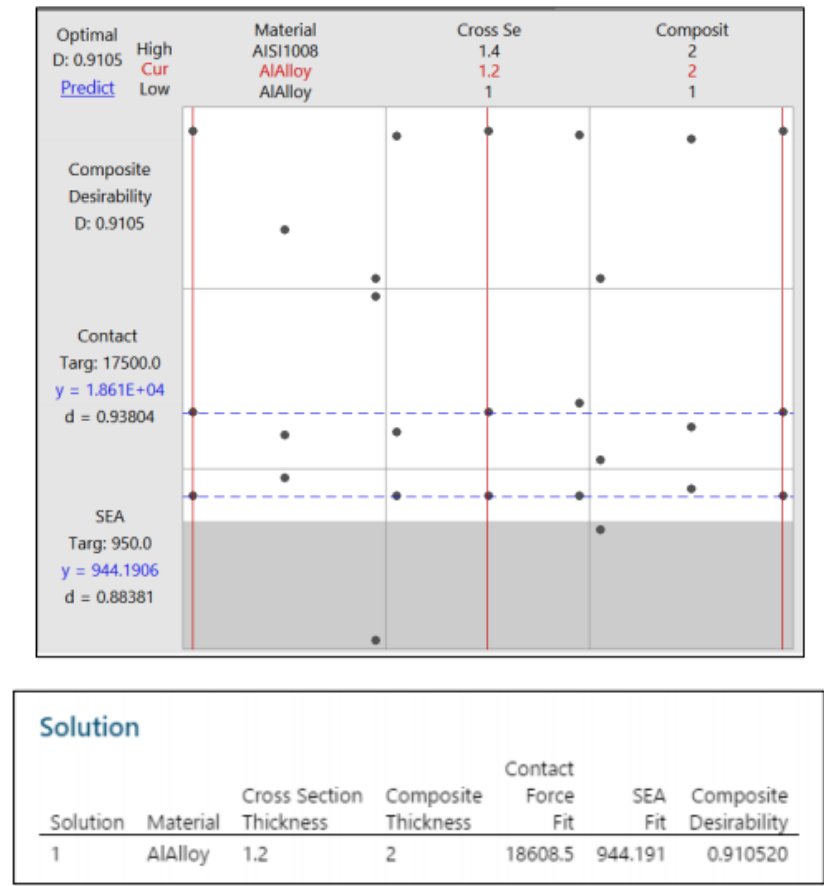

Figure 9: Response optimizer results

Results of the response optimizer show the sample with aluminium alloy with section thickness $1.2 \mathrm{~mm} \&$ composite thickness of $2 \mathrm{~mm}$ can be suited for our requirement.

\section{Contact Force $=18.6 \mathrm{kN}$}

$\mathrm{SEA}=944.19 \mathrm{~J} / \mathrm{kg}$

The numerical simulation results of the same sample show contact force as $17.92 \mathrm{kN} \&$ SEA as $926.32 \mathrm{~J} / \mathrm{kg}$.

\section{CONCLUSIONS}

A comparison study on the side impact beam of a vehicle is carried out with the help of three points bending test numerical simulation on Hyperworks software. Side impact beam with AISI1008 showed the highest resistance force but very low SEA, on other hand Mg Alloy AM60B showed maximum SEA but very low resistance force. Full factorial DOE \& response optimization technique is carried out to optimize the side impact beam for optimum resistance force $\&$ maximum specific energy absorption. From the above numerical simulation results \& optimization, we can conclude that beam with Aluminum alloy AA6061 having a cross-section thickness of $1.2 \mathrm{~mm} \&$ composite thickness of $2 \mathrm{~mm}$ provides an optimum contact force of $17.92 \mathrm{KN} \& \mathrm{SEA}$ as $926.32 \mathrm{~J} / \mathrm{kg}$.

\section{REFERENCES}

1. P. Pawar and S. H. Mankar, (1898) "Crashworthiness Evaluation of Low Weight Recyclable Intrusion Beam for Side Impact," no. 1894, pp. 15.

2. Gopi Kompelli, Prof. Dr. Lukosevicius Vaidas, (2020) "Design and Comparative Analysis of Composite Intrusion Beams in Passenger Car's Side Door”, Kaunas.

3. Kiran C. More, Girish M. Patil, Akash A. Belkhede, (2020) "Design and analysis of side door intrusion beam for automotive safety", Elsevier. 
4. K. Veeraswamy and V. Venkata Sudheer Babu, (2016) "Design and Analysis of a Composite Beam for Side Impact Protection of a Car Door," Int. Res. J. Eng. Technol., vol. 3, no. 2, pp. 464-469.

5. Mohd Adrinata Shaharuzaman, S.M. Sapuan, Muhd Ridzuan Mansor, (2018) "Passenger Car's Side Door Impact Beam: A Review” Journal of Engineering and Technology Vol. 9 No. 1 ISSN: 2180-3811.

6. E. Černiauskas, A. Keršys, V. Lukoševičius, and J. Sapragonas, (2010) "Investigation of anti-intrusion beams in vehicle side doors, "Mechanika, vol. 86, no. 6, pp. 11-16.

7. Yoshio Aoki, Hyoung-Soo Kim \& Goichi Ben, (2009) "Impact strength and response behavior of CFRP guarder belt for side collision of automobiles" International Journal of Crashworthiness Vol. 14, No. 5, 469-476.

8. Rajeev Kumar and H. K. Paliwal, Raghvendra Krishana and Shivangi Yadav,(September 2018) "DEVELOPMENT AND ANALYSIS OF SIDE DOOR INTRUSION BEAM OF SUV" International Journal of Mechanical Engineering and Technology (IJMET) Volume 9, Issue 9.

9. Goichi Ben, Nao Sugimoto, Yoshio Aoki, (02 Apr 2012) "Development of Simulation Technology for Impact Behavior of CFRP/Al Alloy Hybrid Beams in Side Collision of Automobiles", College of Science and Technology, Nihon University,7-24-1, Narashinodai Funabashi, Chiba, 274-8501 Japan Published online.

10. A. Azim, Aidy Ali, B.B. Sahari, (2012) "Performance of Aluminium Alloy Side Door Subjected to Pole Impact Test", Applied Mechanics and Materials Vol 165.

11. Divakara H Basavaraju, (December 2005) “Design and Analysis of a Composite Beam for Side Impact,".Elsevier Science Ltd.

12. Seong Sik Cheon: Dai Gil Lee" \& Kwang Seop Jeong, (Korea. 1997) "Composite side-door impact beams for passenger cars", Department of Mechanical Engineering, Korea Advanced Institute of Science and Technology Taejon 305-701, Korea Department of Textile Engineering, Yeungnam University, Kyongsan 712-749, Elsevier Science Ltd.

13. Kennet Olsson, (October 2006) "New Advanced Ultra-High Strength Steels for the Automotive Industry", AutoTechnology.

14. Pedro Mota Rebelo, (November 2016) "Design Study of a Side Intrusion Beam for Automotive Safety”, Instituto Superior Technicon, Lisboa, Portugal.

15. David C. Viano, Ian V. Lau, Dennis V, (10 May 1989) "BIOMECHANICS OF INJURY IN LATERAL IMPACTS", Biomedical Science Department, General Motors Research Laboratories.

16. Raja Sharmi Raja Husin, Nur Liyana Tajul Lile, Sazali Yaacob, "Optimization of Circular Side Door Beam for Crashworthiness Analysis", International Journal on Advanced Science Engineering Technology.

17. S. Chung Kim Yuen, C. R. Long, G. N. Nurick, (2019) “Analysis of a car door subjected to side pole impact”, Latin American Journals of Solids and Structures.

18. A. Zalani, A. Lashkari, A. Vishwakarma, S. Sharma, (2017) "Design and analysis of door stiffener using finite element analysis against FMVSS 214 pole impact test", IOSR Journal of Mechanical and Civil Engineering (IOSR-JMCE).

19. Narikazu Hashimoto, (June 2017) “Application of Aluminum Extrusions to Automotive Parts”, KOBELCO TECHNOLOGY REVIEW NO. 35 .

20. Sarang Chandrakant Saraf, Prashantkumar S Bajaj, (June -2017) "Design \& Experimentation of Side Impact Beam for Hyundai Verna”, International Research Journal of Engineering and Technology (IRJET). 
21. Amir Radzi Ab Ghani1, Chong Siak Kee, Mohd Zaid Othman, (October 17-2013) "Impact Response of Multi-Grooved Square Column" Canadian Center of Science and Education.

22. Sameer Kumar Devarakonda, (2015) "Magnesium and Its Alloys in Automotive Applications - A Review", Columbia International Publishing, American Journal of Materials Science and Technology Vol. 4 No. 1 pp. 12-30.

23. Basics of DOE retrieved from https://www.isixsigma.com/dictionary/design-of-experiments-doe/ 